\title{
Functional Effects of Two Voltage-Gated Sodium Channel Mutations That Cause Generalized Epilepsy with Febrile Seizures Plus Type 2
}

\author{
Jay Spampanato, ${ }^{1}$ Andrew Escayg, ${ }^{2}$ Miriam H. Meisler, ${ }^{2}$ and Alan L. Goldin ${ }^{1}$ \\ ${ }^{1}$ Department of Microbiology and Molecular Genetics, University of California, Irvine, California 92697-4025, and \\ 2Department of Human Genetics, University of Michigan, Ann Arbor, Michigan 48109-0618
}

Two mutations that cause generalized epilepsy with febrile seizures plus (GEFS + ) have been identified previously in the SCN1A gene encoding the $\alpha$ subunit of the $\mathrm{Na}_{v} 1.1$ voltagegated sodium channel (Escayg et al., 2000). Both mutations change conserved residues in putative voltage-sensing S4 segments, T875M in domain II and R1648H in domain IV. Each mutation was cloned into the orthologous rat channel $\mathrm{rNa}_{\mathrm{v}} 1.1$, and the properties of the mutant channels were determined in the absence and presence of the $\beta 1$ subunit in Xenopus oocytes. Neither mutation significantly altered the voltage dependence of either activation or inactivation in the presence of the $\beta 1$ subunit. The most prominent effect of the T875M mutation was to enhance slow inactivation in the presence of $\beta 1$, with

Generalized epilepsy with febrile seizures plus [GEFS+; Mendelian Inheritance in Man (MIM) \#604233] was first described by Scheffer and Berkovic (1997) as an autosomal dominantly inherited syndrome with a complex and heterogeneous clinical phenotype (Scheffer and Berkovic, 1997; Singh et al., 1999). This syndrome is distinct from febrile seizures, which occur in $\sim 5 \%$ of all children under the age of 6 years and typically are not associated with increased risk of epilepsy in adolescence and adulthood (Nelson and Ellenberg, 1976; Commission on Classification and Terminology of the International League Against Epilepsy, 1989). Scheffer and Berkovic created the diagnosis of GEFS + to identify families in which febrile seizures persist beyond 6 years of age and are associated with generalized epilepsies such as absences, myoclonic seizures, atonic seizures, and myoclonicastatic epilepsy (Scheffer and Berkovic, 1997; Singh et al., 1999).

Linkage analysis identified two genetic loci for GEFS+. GEFS + type $1(\mathrm{GEFS}+1)$ maps to the chromosomal region 19q13.1. A loss-of-function mutation in $S C N 1 B$, the gene encoding the voltage-gated sodium channel $\beta 1$ subunit, was identified in a family with GEFS +1 (Wallace et al., 1998). The mutant $\beta 1$ subunit binds to but does not modulate either neuronal $\mathrm{Na}_{\mathrm{v}} 1.2$ or skeletal muscle $\mathrm{Na}_{\mathrm{v}} 1.4$ sodium channels (Moran and Conti, 2001). GEFS + type $2($ GEFS +2$)$ maps to the chromosomal region

Received Feb. 1, 2001; revised June 25, 2001; accepted July 20, 2001.

This work was supported by National Institutes of Health (NIH) Grants NS26729 (A.L.G.) and NS34609 (M.H.M.). J.S. was supported by NIH Training Grant T32-NS07444, and A.E. acknowledges a fellowship from the American Epilepsy Society with support from UCB Pharma, Smyrna, GA. We thank Annie Lee, Wei Zhou, and A. J. Barela for helpful discussions during the course of this work and Mimi Reyes for excellent technical assistance.

Correspondence should be addressed to A. L. Goldin at the above address. E-mail: AGoldin@uci.edu.

Copyright (C) 2001 Society for Neuroscience $\quad 0270-6474 / 01 / 217481-10 \$ 15.00 / 0$ small effects on the kinetics of recovery from inactivation and use-dependent activity of the channel in both the presence and absence of the $\beta 1$ subunit. The most prominent effects of the $\mathrm{R} 1648 \mathrm{H}$ mutation were to accelerate recovery from inactivation and decrease the use dependence of channel activity with and without the $\beta 1$ subunit. The DIV mutation would cause a phenotype of sodium channel hyperexcitability, whereas the DII mutation would cause a phenotype of sodium channel hypoexcitability, suggesting that either an increase or decrease in sodium channel activity can result in seizures.

Key words: epilepsy; sodium channels; electrophysiology; mutations; GEFS+; SCN1A

2q21-q33 (Baulac et al., 1999; Moulard et al., 1999; Lopes-Cendes et al., 2000), the location of the neuronal sodium channel gene $S C N 1 A$. Escayg et al. (2000) identified the mutations T875M and $\mathrm{R} 1648 \mathrm{H}$ in $S C N 1 A$, which encodes the $\mathrm{Na}_{\mathrm{v}} 1.1$ sodium channel $\alpha$ subunit, in two families with GEFS +2 . This marked the first time that a voltage-gated sodium channel $\alpha$ subunit had been implicated directly in the etiology of inherited epilepsy (for review, see Steinlein and Noebels, 2000).

The sodium channel $\alpha$ subunit is a $260 \mathrm{kDa}$ transmembrane protein with four homologous domains (DI-DIV), each with six transmembrane segments (S1-S6). Both GEFS+ 2 mutations change conserved residues in putative voltage-sensing S4 segments, T875M in DII and R1648H in DIV. Because sodium channels are responsible for the initiation and propagation of action potentials in neurons, a sodium channel mutation that makes the neuron hyperexcitable could result in seizures (Dichter, 1991, 1994). The effects of the R1648H mutation have been examined in two different sodium channels, the neuronal $\mathrm{rNa}_{\mathrm{v}} 1.2$ channel (Kühn and Greeff, 1999) and the skeletal muscle hNa 1.4 channel (Alekov et al., 2000), and the effects of the mutation differed in the two studies.

To determine the effects of the two GEFS +2 mutations in the sodium channel in which they are expressed normally, we cloned each mutation into $\mathrm{rNa}_{\mathrm{v}} 1.1$, the rat channel that is orthologous to the human channel encoded by the $S C N 1 A$ gene. The human and rat orthologs are $98 \%$ identical in amino acid sequence. The electrophysiological properties of the channels were determined in the absence and presence of the $\beta 1$ subunit by expression in Xenopus oocytes. The DII mutation enhanced slow inactivation and had small effects on the kinetics of recovery from inactivation and use-dependent activity of the channel. The DIV mutation dramatically accelerated recovery from inactivation and decreased the use dependence of channel activity. 


\section{MATERIALS AND METHODS}

Site-directed mutagenesis. pNaRat1 encodes a functional $\mathrm{rNa}_{\mathrm{v}} 1.1 \mathrm{cDNA}$ clone positioned between the $5^{\prime}$ and $3^{\prime}$ noncoding regions of the Xenopus $\beta$-globin gene, downstream of a T7 RNA polymerase promoter and upstream of a poly $\left(\mathrm{A}^{+}\right)$tail region (Smith and Goldin, 1998). A $1.9 \mathrm{~kb}$ EcoRI-AccI fragment containing the domain II S4 segment and a $1.7 \mathrm{~kb}$ BstEII-NotI fragment containing the domain IV S4 segment were subcloned into pBSTA and pGEM18B, respectively. Mutagenesis was conducted with the QuikChange Site-Directed Mutagenesis kit (Stratagene, La Jolla, CA) by using the following oligonucleotide primers: T875M (sense), GCAAAGTCCTGGCCCATGCTGAACATGCTCATTAAG; T875M (antisense), CTTAATGAGCATGTTCAGCATGGGCCAGGACTTTGC; R1648H (sense), GGATTGGACGAATCCTACACCTGATCAAAGGCGCC; and R1648H (antisense), GGCGCCTTTGATCAGGTGTAGGATTCGTCCAATCC.

For each mutant, DH5 $\alpha$ bacteria were transformed via electroporation with $D p n I$-treated DNA. The electroporation was performed in parallel with chemical transformation of XL-1 Blue bacteria, using the procedures described in the kit. The products of both transformations were plated on LB-ampicillin agar plates and incubated at $37^{\circ} \mathrm{C}$ for $>16 \mathrm{hr}$. Clones were selected for each mutant, and the desired mutations were verified by the ThermoSequenase Radiolabeled Terminator Cycle Sequencing Kit (United States Biochemicals, Cleveland, OH) and the following primers: T875M (sequencing primer), GACACTCAGCCTGGTAGAAC, and R1648H (sequencing primer), TCCTCTCCATTGTAGGAATG.

At least one clone of the four clones sequenced for each mutant was found to contain the desired mutation with no extraneous mutations. A $1.6 \mathrm{~kb} E c o \mathrm{RI}-M f e I$ fragment from the domain II S4 subclone containing the mutation $T 875 \mathrm{M}$ and a $1.7 \mathrm{~kb}$ BstEII-NotI fragment from the domain IV S4 subclone containing the mutation $\mathrm{R} 1648 \mathrm{H}$ were cloned into the original full-length pNaRat1 plasmid. The new plasmids were termed DII, which contains the T875M mutation, and DIV, which contains the $\mathrm{R} 1648 \mathrm{H}$ mutation.

Expression and electrophysiology. RNA was transcribed in vitro from NotI-linearized DNA templates with the T7 mMessage mMachine kit (Ambion, Austin, TX). The quality of the transcribed mRNA was confirmed by glyoxal gel analysis. Stage V oocytes were removed from adult female Xenopus laevis frogs and prepared as previously described (Goldin, 1991). Oocytes were incubated in ND-96 media, which consisted of (in $\mathrm{mm}$ ) $96 \mathrm{NaCl}, 2 \mathrm{KCl}, 1.8 \mathrm{CaCl}_{2}, 1 \mathrm{MgCl}_{2}$, and 5 HEPES, $\mathrm{pH} 7.5$, supplemented with $0.1 \mathrm{mg} / \mathrm{ml}$ gentamycin, $0.55 \mathrm{mg} / \mathrm{ml}$ pyruvate, and 0.5 mM theophylline. RNA encoding $\mathrm{rNa}_{\mathrm{v}} 1.1$, DII, and DIV channels was injected at $\sim 20 \mathrm{ng} /$ oocyte to obtain current amplitudes between 0.8 and $6 \mu \mathrm{A}$. When the channels were coexpressed with the $\beta 1$ subunit, a 1:10 molar ratio of $\alpha$-to- $\beta 1$ RNA was injected. Oocytes were incubated at $20^{\circ} \mathrm{C}$ for $>40 \mathrm{hr}$ in ND-96 before voltage clamping.

Sodium currents were recorded by using either the two-electrode voltage clamp (TEVC) at room temperature or the cut-open oocyte CA-1 High Performance Oocyte Voltage Clamp (Dagan Instruments, Minneapolis, $\mathrm{MN}$ ) at $20^{\circ} \mathrm{C}$, with a DigiData $1321 \mathrm{~A}$ interface (Axon Instruments, Foster City, CA) and pClamp 8.0 software (Axon Instruments) as previously described (Patton and Goldin, 1991; Kontis et al., 1997). On the TEVC the currents were recorded in ND-96 without supplements in the absence and presence of $400 \mathrm{~nm}$ tetrodotoxin (TTX). Capacitive transients were eliminated by subtraction of TTX-recorded currents. Slow-gated properties were analyzed via a baseline subtraction method in which the average current amplitude recorded during the last $1 \mathrm{msec}$ of a given test pulse was subtracted from the peak current amplitude of that same test pulse before normalization.

The voltage dependence of activation was analyzed via a step protocol in which oocytes were depolarized from a holding potential of $-100 \mathrm{mV}$ to a range of potentials from -95 to $+50 \mathrm{mV}$ in $5 \mathrm{mV}$ increments. Peak currents were normalized to the maximum peak current and plotted against voltage. To calculate a reversal potential, we fit the resulting $I-V$ curve of each data set individually with the equation:

$$
I=\left[1+\exp \left(-0.03937 \cdot z \cdot\left(V-V_{1 / 2}\right)\right)\right]^{-1} \cdot g \cdot\left(V-V_{\mathrm{r}}\right),
$$

where $I$ is the current amplitude, $z$ is the apparent gating charge, $V$ is the potential of the given pulse, $V_{1 / 2}$ is the half-maximal voltage, $g$ is a factor related to the number of open channels during the given pulse, and $V_{\mathrm{r}}$ is the reversal potential. Then conductance was calculated directly by using the equation:

$$
G=I /\left(V-V_{\mathrm{r}}\right)
$$

where $G$ is conductance and $I, V$, and $V_{\mathrm{r}}$ are as described above. The conductance values were fit with the two-state Boltzmann equation:

$$
G=1 /\left(1+\exp \left[-0.03937 \cdot z \cdot\left(V-V_{1 / 2}\right)\right]\right),
$$

where $z$ is the apparent gating charge, $V$ is the potential of the given pulse, and $V_{1 / 2}$ is the potential for half-maximal activation.

The voltage dependence of steady-state inactivation was determined via a two-step protocol in which a conditioning pulse was applied from a holding potential of $-100 \mathrm{mV}$ to a range of potentials from -100 to $+15 \mathrm{mV}$ in $5 \mathrm{mV}$ increments for $100 \mathrm{msec}$, followed immediately by a test pulse to $-5 \mathrm{mV}$. The peak current amplitudes during the subsequent test pulses were normalized to the peak current amplitude during the first test pulse, plotted against the potential of the conditioning pulse, and fit with the two-state Boltzmann equation:

$$
I=1 /\left(1+\exp \left[\left(V-V_{1 / 2}\right) / a\right]\right),
$$

where $I$ is equal to the test pulse current amplitude, $V$ is the potential of the conditioning pulse, $V_{1 / 2}$ is the voltage for half-maximal inactivation, and $a$ is the slope factor.

Recovery from inactivation was analyzed with three separate twopulse protocols. Each protocol began with a conditioning depolarization from a holding potential of -100 to $-5 \mathrm{mV}$ for $50 \mathrm{msec}$, which inactivated $>95 \%$ of the channels. This was followed by a decreasing recovery time interval at $-100 \mathrm{mV}$ and a test depolarization to $-5 \mathrm{mV}$. The three protocols differed only in the maximum length of recovery time and the time interval by which that recovery period decreased: $25 \mathrm{msec}$ maximum and $1 \mathrm{msec}$ decrements in the short protocol, $200 \mathrm{msec}$ maximum and 5 msec decrements in the intermediate protocol, and $3000 \mathrm{msec}$ maximum and $100 \mathrm{msec}$ decrements in the long protocol. Fractional recovery was calculated by dividing the maximum current amplitude during the test pulse by the maximum current amplitude of the corresponding conditioning pulse. The recovery data were fit with either the double exponential equation:

$$
I=1-\left[A_{1} \cdot \exp \left(-t / \tau_{1}\right)+A_{2} \cdot \exp \left(-t / \tau_{2}\right)\right]
$$

or the triple exponential equation:

$$
I=1-\left[A_{1} \cdot \exp \left(-t / \tau_{1}\right)+A_{2} \cdot \exp \left(-t / \tau_{2}\right)+A_{3} \cdot \exp \left(-t / \tau_{3}\right)\right],
$$

where $A_{1}, A_{2}$, and $A_{3}$ are the relative percentages of current that recovered with the time constants $\tau_{1}, \tau_{2}$, and $\tau_{3}$, and $t$ is the recovery time.

Use dependence was analyzed at frequencies of 10,20 , and $39 \mathrm{~Hz}$ by using $17.5 \mathrm{msec}$ depolarizations to $-10 \mathrm{mV}$ from a holding potential of $-100 \mathrm{mV}$. The protocols were performed for $2 \mathrm{sec}$ at $10 \mathrm{~Hz}, 2.5 \mathrm{sec}$ at 20 $\mathrm{Hz}$, and $2.56 \mathrm{sec}$ at $39 \mathrm{~Hz}$, which was long enough for the current to have reached an equilibrium value in each case. Peak current amplitudes were normalized to the peak current amplitude during the first depolarization and plotted against pulse number.

The kinetics of fast inactivation were analyzed by using the cut-open oocyte voltage clamp, with the bath solution maintained at $20^{\circ} \mathrm{C}$ with an HCC-100A Temperature Controller (Dagan). The external solution consisted of (in mM) 120 sodium methanesulfonate, 10 HEPES, and 1.8 calcium methanesulfonate, $\mathrm{pH}$ 7.5. The internal solution consisted of (in mM) $88 \mathrm{~K}_{2} \mathrm{SO}_{4}, 10$ EGTA, 10 HEPES, and $10 \mathrm{Na}_{2} \mathrm{SO}_{4}, \mathrm{pH} 7.5 . \mathrm{P} / 4$ subtraction was used to eliminate capacitive transients and leak currents. Currents were elicited via a step protocol in which oocytes were depolarized from a holding potential of $-100 \mathrm{mV}$ to a range of potentials from -95 to $+50 \mathrm{mV}$ in $5 \mathrm{mV}$ increments. Inactivation time constants were determined by the Chebyshev method to fit each trace with either the single exponential equation:

$$
I=A_{\text {Slow }} \cdot \exp \left[-(t-K) / \tau_{\text {Slow }}\right]+C,
$$

or the double exponential equation:

$$
I=A_{\text {Fast }} \cdot \exp \left[-(t-K) / \tau_{\text {Fast }}\right]+A_{\text {Slow }} \cdot \exp \left[-(t-K) / \tau_{\text {Slow }}\right]+C,
$$

where $I$ is the current, $A_{\text {Fast }}$ and $A_{\text {Slow }}$ are the relative proportions of current inactivating with the time constants $\tau_{\text {Fast }}$ and $\tau_{\text {Slow }}, K$ is the time shift, and $C$ is the steady-state asymptote. The time shift was selected manually as the point at which the macroscopic current began to inactivate exponentially.

The voltage dependence of steady-state slow inactivation was determined via a modified two-step protocol in which a conditioning pulse was applied from a holding potential of $-120 \mathrm{mV}$ to a specified range of 
potentials between -120 and $-10 \mathrm{mV}$ for a period of $60 \mathrm{sec}$. The conditioning pulse was followed immediately by a hyperpolarization to $-120 \mathrm{mV}$ for $20 \mathrm{msec}$ to allow for recovery from fast inactivation and a test pulse to $-5 \mathrm{mV}$. The peak current amplitudes during the subsequent test pulses were normalized to the peak current amplitude during the first test pulse, plotted against the potential of the conditioning pulse, and fit with the two-state Boltzmann equation described earlier:

$$
I=1 /\left(1+\exp \left[\left(V-V_{1 / 2}\right) / a\right]\right) .
$$

The rate of entry into the slow-inactivated state was analyzed by using a two-step protocol with a variable length conditioning pulse, followed by a test pulse. The conditioning potential of $-45 \mathrm{mV}$ was applied from a holding potential of $-120 \mathrm{mV}$ for a variable length of time beginning with $0 \mathrm{sec}$ and ending with $60 \mathrm{sec}$ in $5 \mathrm{sec}$ increments. The conditioning pulse was followed immediately by a hyperpolarization to $-120 \mathrm{mV}$ for $20 \mathrm{msec}$ to allow for recovery from fast inactivation and a test pulse to -5 $\mathrm{mV}$. The peak current amplitudes during the subsequent test pulses were normalized to the peak current amplitude during the first test pulse, plotted against the period of the conditioning pulse, and fit with the double exponential equation:

$$
I=A_{\text {Slow }} \cdot \exp \left(-t / \tau_{\text {Slow }}\right)+A_{\text {Fast }} \cdot \exp \left(-t / \tau_{\text {Fast }}\right),
$$

where $I$ is the current, $A_{\text {Fast }}$ and $A_{\text {Slow }}$ are the relative proportions of current inactivating with the time constants $\tau_{\text {Fast }}$ and $\tau_{\text {Slow }}$, and $t$ is the period of the conditioning pulse. The rate of entry into the slowinactivated state also was analyzed with a $-10 \mathrm{mV}$ conditioning pulse over a period of $28.5 \mathrm{sec}$. At this potential, however, the conditioning pulse length was varied in a nonlinear manner to collect more data during the first $10 \mathrm{sec}$, because $>80 \%$ of the current inactivated in $<10 \mathrm{sec}$.

Recovery from slow inactivation was analyzed with two separate two-pulse protocols. Each protocol began with a conditioning depolarization from a holding potential of -120 to $-5 \mathrm{mV}$ for $60 \mathrm{sec}$, which inactivated $>95 \%$ of the channels. This was followed by a decreasing recovery time interval at $-120 \mathrm{mV}$, an additional $20 \mathrm{msec}$ at $-120 \mathrm{mV}$, and a test depolarization to $-5 \mathrm{mV}$. Like the fast inactivation recovery protocols, these protocols differed only in the maximum length of recovery time and the time interval by which that recovery period decreased. The short protocol used a $14 \mathrm{sec}$ maximum and $2 \mathrm{sec}$ decrements and the long protocol used a $60 \mathrm{sec}$ maximum and $10 \mathrm{sec}$ decrements. Fractional recovery was calculated by dividing the maximum current amplitude during the test pulse by the average maximum current amplitude during five single-step depolarizations to $-5 \mathrm{mV}$ recorded before each recovery protocol and was plotted against the length of the recovery interval. The recovery data were fit with a double exponential equation:

$$
I=1-\left[A_{\text {Fast }} \cdot \exp \left(-t / \tau_{\text {Fast }}\right)+A_{\text {Slow }} \cdot \exp \left(-t / \tau_{\text {Slow }}\right)\right],
$$

where $I$ is the current, $A_{\text {Fast }}$ and $A_{\text {Slow }}$ are the relative percentages of current that recovered with the time constants $\tau_{\text {Fast }}$ and $\tau_{\text {Slow }}$, and $t$ is the recovery time.

\section{RESULTS}

\section{The GEFS + 2 mutations do not affect the voltage dependence of activation or inactivation significantly}

Escayg et al. (2000) previously identified two mutations in the $S C N 1 A$ gene encoding the $\mathrm{Na}_{\mathrm{v}} 1.1$ sodium channel that cause GEFS +2 . The two mutations are a substitution of methionine for threonine 875 (T875M) in domain II and a substitution of histidine for arginine $1648(\mathrm{R} 1648 \mathrm{H})$ in domain IV. To determine how these mutations affect sodium channel function, we constructed each mutation in the orthologous rat channel $\mathrm{rNa}_{\mathrm{v}} 1.1$. Then the properties of the mutant channels were compared with those of the wild-type channel expressed in Xenopus oocytes by using the cut-open oocyte voltage clamp and the two-electrode voltage clamp. The channels were compared in the absence and presence of the $\beta 1$ subunit. Figure 1 shows sample cut-open oocyte voltage-clamp recordings of the currents from the wildtype $\left(\mathrm{rNa}_{\mathrm{v}} 1.1\right)$ and the two mutant channels during depolarizations between -50 and $+50 \mathrm{mV}$ in $10 \mathrm{mV}$ intervals. For all three samples the injection of $\sim 20 \mathrm{ng}$ of RNA resulted in current

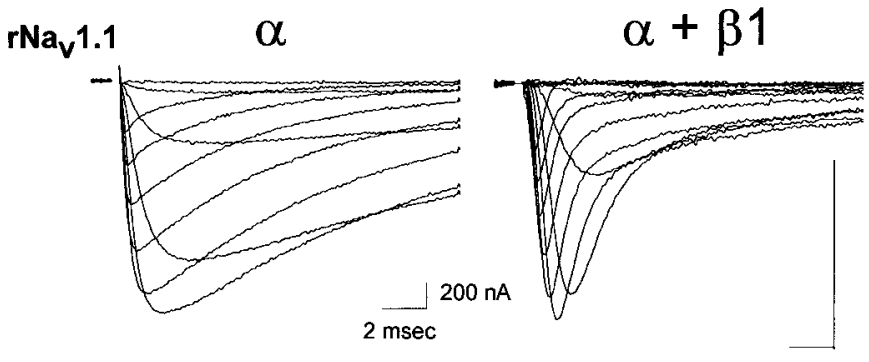

\section{DII (T875M)}
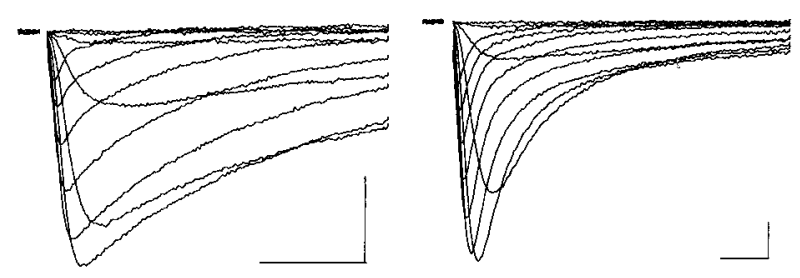

\section{DIV (R1648H)}
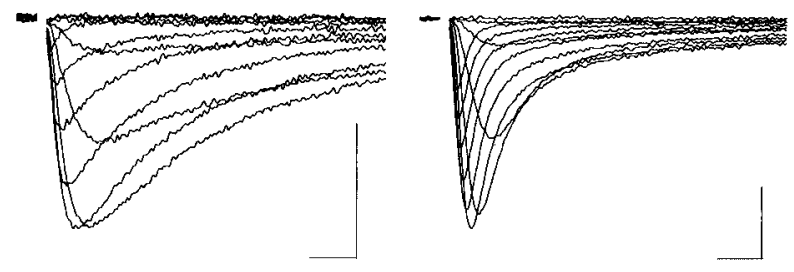

Figure 1. Sample sodium channel currents from wild-type $\mathrm{rNa}_{\mathrm{v}} 1.1$ and GEFS +2 mutant channels. Currents were recorded for the wild-type $\mathrm{rNa}_{\mathrm{v}} 1.1$, DII (T875M), and DIV (R1648H) mutants expressed as $\alpha$ subunits alone and as $\alpha+\beta 1$ subunits. Mutant and wild-type channels were expressed in Xenopus oocytes, and currents were recorded at $20^{\circ} \mathrm{C}$ by using the cut-open oocyte voltage clamp, as described in Materials and Methods. Membrane depolarizations from a holding potential of -100 $\mathrm{mV}$ to a range of potentials from -50 to $+50 \mathrm{mV}$ in $10 \mathrm{mV}$ increments are shown. Calibration: $2 \mathrm{msec}, 200 \mathrm{nA}$.

amplitudes between 1 and $5 \mu \mathrm{A}$, suggesting that the mutations had no significant effects on the translation or processing of the channel proteins. As can be seen, there were no dramatic differences in channel kinetics between the mutant and wild-type channels in either the absence or presence of the $\beta 1$ subunit.

Because both mutations are located in $\mathrm{S} 4$ regions that function as voltage sensors for the channel, it was possible that one or both mutations might alter the voltage dependence of either activation or inactivation. A shift in the voltage dependence of activation of the $\mathrm{Na}_{\mathrm{v}} 1.6$ neuronal sodium channel has been demonstrated previously to result from a mutation that causes ataxia in med ${ }^{j o}$ mice (Smith and Goldin, 1999). We therefore compared the voltage dependence of activation and inactivation of the mutant and wild-type channels in the absence and presence of the $\beta 1$ subunit. The data are shown in Figure 2, with the parameters of the Boltzmann fits displayed in Table 1.

The voltage dependence of activation for the DII (T875M, gray circles) and the DIV (R1648H, black circles) mutants was not significantly different from that of the wild-type channel $\left(\mathrm{rNa}_{\mathrm{v}} 1.1\right.$, white circles) when expressed as either the $\alpha$ subunit alone or as $\alpha$ $+\beta 1$ subunits (Fig. 2). There were no significant differences in either the $V_{1 / 2}$ or slope values for any of the channels (Table 1$)$. In 
Figure 2. Voltage dependence of activation and steady-state inactivation for wild-type $\mathrm{rNa}_{\mathrm{v}} 1.1$ and GEFS +2 mutant channels. The voltage dependencies of activation (circles) and inactivation (diamonds) were determined for the wild-type $\mathrm{rNa}_{\mathrm{v}} 1.1$ (white symbols), DII ( gray symbols), and DIV (black symbols) mutants expressed as $\alpha$ subunits alone $(A)$ and as $\alpha+\beta 1$ subunits $(B)$. Sodium currents were recorded from a holding potential of $-100 \mathrm{mV}$ by depolarizations to a range of potentials from -95 to $+50 \mathrm{mV}$ in $5 \mathrm{mV}$ increments. Conductance values were calculated by dividing the peak current amplitude by the driving force at each potential and normalizing to the maximum conductance, as described in Materials and Methods. The values shown are averages; the error bars indicate SD. The data were fit with a twostate Boltzmann equation, and the parameters of the fits are shown in Table 1 . The voltage dependence of inactivation was determined by using a two-step protocol in which a conditioning pulse was applied from a holding potential of $-100 \mathrm{mV}$, consisting of $100 \mathrm{msec}$ depolarizations to a range of potentials from -100 to $+15 \mathrm{mV}$ in $5 \mathrm{mV}$ increments, followed by a test pulse to $-5 \mathrm{mV}$. The peak current amplitude during each test pulse was normalized to the current amplitude of the first test pulse and plotted as a function of the conditioning pulse potential. The values shown are averages; the error bars indicate SD. The data were fit with a two-state Boltzmann equation, and the parameters of the fits are shown in Table 1.
A

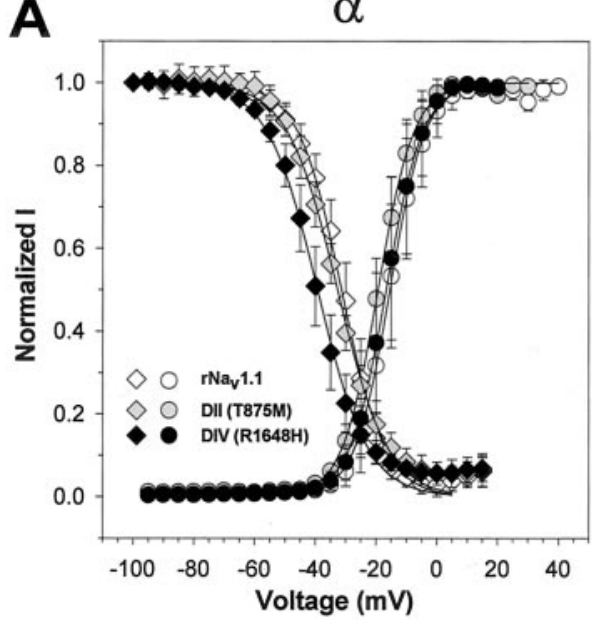

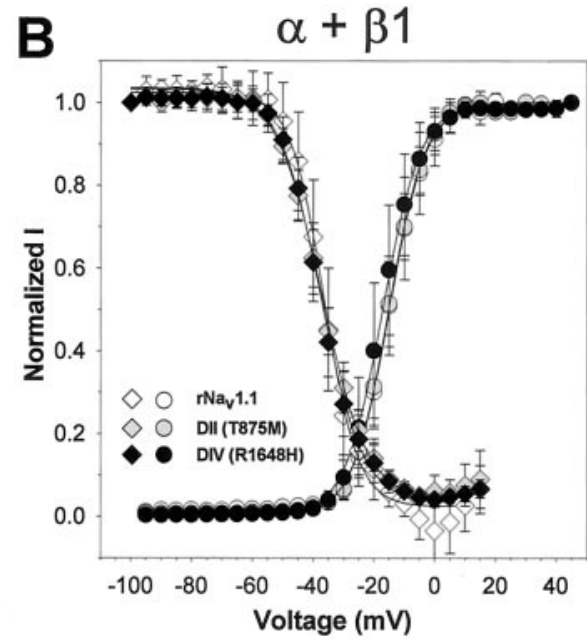

Table 1. Parameters of voltage dependence and recovery from inactivation

Recovery from inactivation

\begin{tabular}{|c|c|c|c|c|c|c|c|c|c|c|c|c|c|}
\hline \multirow[b]{3}{*}{ Channel } & \multirow{2}{*}{\multicolumn{3}{|c|}{ Activation }} & \multirow{2}{*}{\multicolumn{3}{|c|}{ Inactivation }} & \multirow{2}{*}{\multicolumn{2}{|c|}{$\tau_{1}$}} & \multirow{2}{*}{\multicolumn{2}{|c|}{$\tau_{2}$}} & \multirow{2}{*}{\multicolumn{3}{|c|}{$\tau_{3}$}} \\
\hline & & & & & & & & & & & & & \\
\hline & $V_{1 / 2}(\mathrm{mV})$ & $z\left(e_{0}\right)$ & $n$ & $V_{1 / 2}(\mathrm{mV})$ & $a(\mathrm{mV})$ & $n$ & msec & Percentage & msec & Percentage & msec & Percentage & $n$ \\
\hline $\mathrm{rNa}_{\mathrm{v}} 1.1$ & $-15.3 \pm 3.9$ & $4.9 \pm 0.8$ & 8 & $-31.4 \pm 2.6$ & $7.0 \pm 1.0$ & 12 & $1.8 \pm 0.3$ & $42 \pm 6$ & $55.3 \pm 20.7$ & $36 \pm 10$ & $906 \pm 738$ & $21 \pm 14$ & f \\
\hline DII & $-19.3 \pm 2.3$ & $4.5 \pm 0.6$ & 8 & $-32.7 \pm 1.9$ & $8.3 \pm 1.2$ & 12 & $2.1 \pm 0.02$ & $20 \pm 4^{b}$ & $47.4 \pm 8.6$ & $37 \pm 7$ & $224 \pm 44$ & $43 \pm 10$ & 4 \\
\hline DIV & $-16.6 \pm 4.4$ & $4.9 \pm 0.5$ & 8 & $-39.2 \pm 2.9^{b}$ & $8.1 \pm 0.9$ & 9 & $2.7 \pm 0.6$ & $74 \pm 8^{b}$ & $16.1 \pm 9.4^{b}$ & $21 \pm 8$ & $\mathrm{ND}^{a}$ & $\mathrm{ND}^{a}$ & 7 \\
\hline $\mathrm{rNa}_{\mathrm{v}} 1.1+\beta 1$ & $-14.8 \pm 3.0$ & $4.4 \pm 0.7$ & 4 & $-36.1 \pm 2.9$ & $5.5 \pm 0.4$ & 4 & $1.9 \pm 0.6$ & $80 \pm 24$ & $51.9 \pm 20.4$ & $15 \pm 3$ & $\mathrm{ND}^{a}$ & $\mathrm{ND}^{a}$ & 4 \\
\hline $\mathrm{DII}+\beta 1$ & $-15.2 \pm 2.4$ & $4.4 \pm 0.3$ & 8 & $-37.0 \pm 1.7$ & $7.5 \pm 1.2^{c}$ & 9 & $1.7 \pm 0.1$ & $77 \pm 9$ & $79.1 \pm 4.5^{c}$ & $20 \pm 3$ & $\mathrm{ND}^{a}$ & $\mathrm{ND}^{a}$ & 6 \\
\hline $\mathrm{DIV}+\beta 1$ & $-17.0 \pm 4.0$ & $4.5 \pm 0.7$ & 9 & $-37.0 \pm 2.5$ & $7.0 \pm 0.9^{c}$ & 10 & $1.0 \pm 0.1^{c}$ & $86 \pm 6$ & $17.7 \pm 6.8^{c}$ & $9 \pm 1^{c}$ & $\mathrm{ND}^{a}$ & $\mathrm{ND}^{a}$ & 5 \\
\hline
\end{tabular}

${ }^{a}$ Not determined because the recovery of these channels was best fit with a double exponential.

${ }^{b}$ Indicates a statistically significant difference from wild-type $\mathrm{rNa}_{\mathrm{v}} 1.1 \alpha$ alone at $p<0.05$.

${ }^{c}$ Indicates a statistically significant difference from wild-type $\mathrm{rNa}_{\mathrm{v}} 1.1 \alpha+\beta 1$ at $p<0.05$.

addition, the presence of the $\beta 1$ subunit did not alter the voltage dependence of activation significantly, in agreement with previously published data that demonstrated no significant effects of the $\beta 1$ subunit on the voltage dependence of activation of $\mathrm{rNa}_{\mathrm{v}} 1.1$ or $\mathrm{rNa}_{\mathrm{v}} 1.2$ channels (Smith and Goldin, 1998).

The voltage dependence of inactivation was not significantly different between the DII (T875M, gray diamonds) and wild-type $\left(\mathrm{rNa}_{\mathrm{v}} 1.1\right.$, white diamonds) channels when the $\alpha$ subunits were expressed alone (Fig. 2A, Table 1). However, the DIV (R1648H, black diamonds) mutant $\alpha$ subunit displayed a shift of $\sim 8 \mathrm{mV}$ in the hyperpolarized direction. When the channels were coexpressed with the $\beta 1$ subunit, there were no significant differences among the DII (T875M, gray diamonds), DIV (R1648H, black diamonds), and wild-type ( $\mathrm{rNa}_{\mathrm{v}} 1.1$, white diamonds) channels. Coexpression of $\beta 1$ shifted the $V_{1 / 2}$ of inactivation for both the wild-type and the DII channels in the negative direction but did not alter the $V_{1 / 2}$ of inactivation for the DIV mutant channel significantly. The negative shift in the $V_{1 / 2}$ of inactivation is similar but less pronounced than previously observed (Smith and Goldin, 1998). In summary, neither of the GEFS +2 mutations significantly altered the voltage dependence of activation or inactivation.

\section{The DIV mutant alters the kinetics of inactivation}

Because neither mutation markedly changed the voltage dependence of channel gating, it was possible that the neuronal phenotype in GEFS +2 could result from alterations in the kinetics of inactivation. Based on the sample currents shown in Figure 1, the DIV mutant appeared to have small effects on inactivation kinetics when expressed as the $\alpha$ subunit alone. To quantify these effects, we fit current traces similar to those shown in Figure 1 with either a single or a double exponential equation, as described in Materials and Methods. In the absence of the $\beta 1$ subunit, wild-type $\mathrm{rNa}_{\mathrm{v}} 1.1$ was best fit with a single exponential equation for potentials from -35 to $+10 \mathrm{mV}$, resulting in a single $\tau_{\text {slow }}$ (Fig. 3A, white triangles). The DII (T875M, gray triangles) and DIV (R1648H, black triangles) channels were best fit with a single exponential for potentials from -30 to $+10 \mathrm{mV}$ and -35 to +10 $\mathrm{mV}$, respectively. A double exponential equation resulting in a $\tau_{\text {slow }}$ (triangles) and a $\tau_{\text {fast }}$ (circles) was used to fit wild-type $\mathrm{rNa}_{\mathrm{v}} 1.1$ and both GEFS +2 mutants for potentials positive to +10 $\mathrm{mV}$. When expressed as the $\alpha$ subunit alone, the DII mutant displayed kinetics of inactivation similar to that of the wild-type channel. In addition, the percentage of the fast component was 


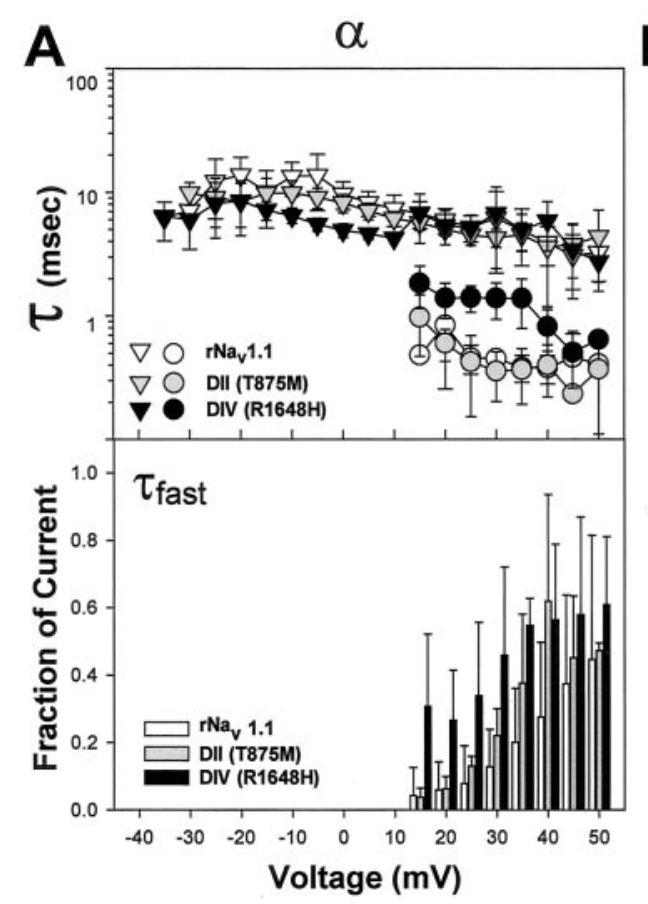

Figure 3. Kinetics of fast inactivation of wildtype $\mathrm{rNa}_{\mathrm{v}} 1.1$ and GEFS +2 mutant channels. Sodium currents were recorded from oocytes expressing wild-type $\mathrm{rNa}_{\mathrm{v}} 1.1$ (white symbols and bars), DII (gray symbols and bars), and DIV (black symbols and bars) channels, as described in the legend to Figure 1. Current traces were fit with either a single or a double exponential equation, as described in Materials and Methods, and time constants for the fast $\left(\tau_{\text {fast }}\right.$, circles $)$ and slow $\left(\tau_{\text {slow }}\right.$, triangles $)$ components of fast inactivation are plotted on a logarithmic scale in the top panels for $\alpha$ subunits alone $(A)$ and $\alpha+$ $\beta 1$ subunits $(B)$. The bottom panels indicate the fraction of current inactivating with $\tau_{\text {fast }}$. In all cases the sum of the components is one. The values shown are averages; the error bars indicate SD. Sample sizes were $\mathrm{rNa}_{\mathrm{v}} 1.1 \alpha$ (4), DII $\alpha$ (5), DIV $\alpha$ (4), $\mathrm{rNa}_{\mathrm{v}} 1.1 \alpha+\beta 1$ (4), DII $\alpha+\beta 1$ (5), DIV $\alpha+\beta 1$ (7). similar for the DII mutant and $\mathrm{rNa}_{\mathrm{v}} 1.1$ wild-type channels. The DIV mutant displayed a slower $\tau_{\text {fast }}$ than wild-type $\mathrm{rNa}_{\mathrm{v}} 1.1$ for potentials positive to $+10 \mathrm{mV}$ and a faster $\tau_{\text {slow }}$ for potentials between -10 and $+10 \mathrm{mV}$. The DIV mutant also inactivated a larger percentage of current than did wild-type $\mathrm{rNa}_{\mathrm{v}} 1.1$ with $\tau_{\text {fast }}$ for the potentials of +15 and $+20 \mathrm{mV}$.

Coexpression of both mutants with the $\beta 1$ subunit resulted in $\tau_{\text {fast }}$ values that were similar to those of wild-type $\mathrm{rNa}_{\mathrm{v}} 1.1$ at all potentials at which $\tau_{\text {fast }}$ was detected (Fig. $3 B$ ). For each mutant and wild-type $\mathrm{rNa}_{\mathrm{v}} 1.1, \tau_{\text {fast }}$ was detected first at $-25 \mathrm{mV}$. The DIV mutant again displayed $\tau_{\text {slow }}$ values that were slightly faster than those of wild-type $\mathrm{rNa}_{\mathrm{v}} 1.1$ at potentials between -5 and +10 $\mathrm{mV}$, with a similar percentage of current inactivating with $\tau_{\text {fast }}$ at all potentials. The DII mutant displayed similar kinetics to that of wild-type $\mathrm{rNa}_{\mathrm{v}} 1.1$, with a similar ratio of current inactivating with $\tau_{\text {fast }}$ at all potentials.

\section{The DIV mutant displays a more rapid recovery from inactivation than does wild-type $\mathrm{rNa}_{\mathrm{v}} \mathbf{1 . 1}$}

Inactivated channels experience a latency period during which they recover from the inactivated state to the closed state. This transition to the closed state must occur before the channels are capable of opening in response to subsequent membrane depolarizations. A mutation that alters this property would result in channels that are capable of either more rapid recovery, resulting in hyperexcitability, or less rapid recovery, resulting in hypoexcitability. Neuronal hyperexcitability is known to be the cause of some seizure activity (Dichter, 1991, 1994). Separate diseasecausing mutations in both $\mathrm{Na}_{\mathrm{v}} 1.4$ and $\mathrm{Na}_{\mathrm{v}} 1.5$ have been shown to result in hyperexcitability via the mechanism of more rapid recovery from inactivation (Hayward et al., 1996; Chen et al., 1998). We therefore analyzed the effects of each GEFS +2 mutation on recovery from inactivation in comparison to wild-type $\mathrm{rNa}_{\mathrm{v}} 1.1$ in the presence and absence of the $\beta 1$ subunit, as described in Materials and Methods (Fig. 4, Table 1).

In the absence of $\beta 1$ the DII mutant (Fig. $4 A$, gray circles) displayed slower recovery than wild-type $\mathrm{rNa}_{\mathrm{v}} 1.1$ (white circles) in the early-to-middle time period, whereas the DIV mutant (black circles) displayed faster recovery at all times. The time for $\sim 50 \%$ recovery was $45 \mathrm{msec}$ for the DII mutant, $12 \mathrm{msec}$ for the wild-type $\mathrm{rNa}_{\mathrm{v}} 1.1$, and $<3 \mathrm{msec}$ for the DIV mutant. The DIV mutant recovered $95 \%$ of the total current in $<18 \mathrm{msec},>20$ times faster than wild-type $\mathrm{rNa}_{\mathrm{v}} 1.1$ and DII mutant channels, which required between 400 and $500 \mathrm{msec}$ for comparable levels of recovery. Data for the rapidly recovering DIV mutant were best fit with a double exponential equation, in contrast to the DII mutant and wild-type $\mathrm{rNa}_{\mathrm{v}} 1.1$ channels, both of which were fit with triple exponential equations (Table 1).

Coexpression of the $\beta 1$ subunit with wild-type $\mathrm{rNa}_{\mathrm{v}} 1.1$ has been shown previously to result in a more rapid recovery from inactivation (Smith and Goldin, 1998). Coexpression of the $\beta 1$ subunit with the GEFS +2 mutants also resulted in more rapid recovery from inactivation when compared with $\alpha$ subunit channels (Fig. $4 B)$. In the presence of the $\beta 1$ subunit, recovery from inactivation was similar for the DII mutant (gray circles) and the wild-type $\mathrm{rNa}_{\mathrm{v}} 1.1$ (white circles). The DIV mutant (black circles) demonstrated more rapid recovery from inactivation than either wildtype $\mathrm{rNa}_{\mathrm{v}} 1.1$ or DII mutant channels even when coexpressed with the $\beta 1$ subunit. The DIV mutant recovered $95 \pm 1 \%$ of the total current at $8 \mathrm{msec}$, whereas the DII mutant and wild-type $\mathrm{rNa}_{\mathrm{v}} 1.1$ each required $\sim 100 \mathrm{msec}$ for comparable recovery. In the presence of the $\beta 1$ subunit, recovery from inactivation for all three channels was best fit with a double exponential equation (Table 1).

The DIV mutant achieved a more rapid recovery by two different effects. When expressed as an $\alpha$ subunit alone, a larger percentage of the total current recovered with the shortest time constant $\left(\tau_{1}\right)$ and the remaining portion of the total current recovered with a more rapid second time constant $\left(\tau_{2}\right)$ as compared with both the wild-type $\mathrm{rNa}_{\mathrm{v}} 1.1$ channel and the DII mutant (Table 1). When coexpressed with the $\beta 1$ subunit, however, the DIV mutant recovered with a more rapid $\tau_{1}$ as compared with the wild-type $\mathrm{rNa}_{\mathrm{v}} 1.1$ channel, although the percentage of 
Figure 4. Recovery from inactivation for wild-type $\mathrm{rNa}_{\mathrm{v}} 1.1$ and GEFS + 2 mutant channels. Recovery from inactivation was determined by using three separate twopulse protocols for wild-type $\mathrm{rNa}_{\mathrm{v}} 1.1$ (white symbols), DII (gray symbols), and DIV (black symbols) channels. Each protocol was performed with a holding potential of $-100 \mathrm{mV}$ and consisted of a conditioning depolarization to $-5 \mathrm{mV}$ for 50 msec (which inactivated $>95 \%$ of the channels), a decreasing recovery time interval at $-100 \mathrm{mV}$, and a test depolarization to $-5 \mathrm{mV}$. The three protocols differed only in the maximum length of recovery time and the time interval by which that recovery period decreased: 25 msec maximum and $1 \mathrm{msec}$ decrements in the early protocol, $200 \mathrm{msec}$ maximum and $5 \mathrm{msec}$ decrements in the intermediate protocol, and $3000 \mathrm{msec}$ maximum and $100 \mathrm{msec}$ decrements in the late protocol. Fractional recovery was calculated by dividing the maximum current amplitude of the test pulse by the maximum current amplitude of the corresponding conditioning pulse. Fractional recovery is plotted on a log scale as a function of time for $\alpha$ subunits alone $(A)$ and $\alpha+\beta 1$ subunits $(B)$. The values shown are averages; the error bars indicate SD.
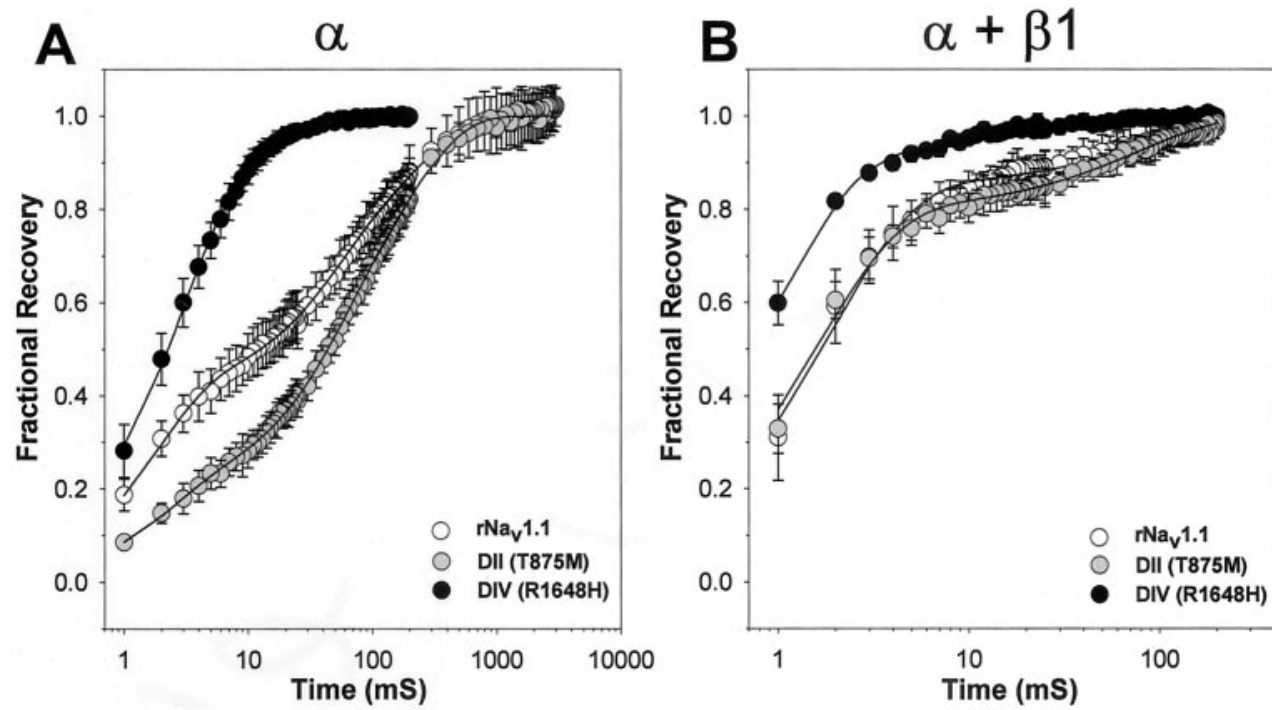

Figure 5. Frequency dependence of wild-type $\mathrm{rNa}_{\mathrm{v}} 1.1$ and GEFS +2 mutant channels. Use dependence was analyzed at 10,20 , and $39 \mathrm{~Hz}$ for wildtype $\mathrm{rNa}_{\mathrm{v}} 1.1$ (white symbols), DII ( gray symbols), and DIV (black symbols) channels. Currents were elicited at each frequency by using $17.5 \mathrm{msec}$ depolarizations to $-10 \mathrm{mV}$ from a holding potential of $-100 \mathrm{mV}$. Each protocol was performed until an equilibrium current had been reached: $2 \mathrm{sec}$ at 10 $\mathrm{Hz}, 2.5 \mathrm{sec}$ at $20 \mathrm{~Hz}$, and $2.56 \mathrm{sec}$ at 39 Hz. Peak current amplitudes were normalized to the initial peak current amplitude and plotted against pulse number for $\alpha$ subunits alone $(A$, circles $)$ and $\alpha+\beta 1$ subunits ( $B$, diamonds). The values shown are averages; the error bars indicate SD. Sample sizes were $\mathrm{rNa}_{\mathrm{v}} 1.1 \alpha(5)$, DII $\alpha(5), \operatorname{DIV} \alpha(5)$, $\mathrm{rNa}_{\mathrm{v}} 1.1 \alpha+\beta 1$ (3), DII $\alpha+\beta 1$ (5), $\operatorname{DIV} \alpha+\beta 1(5)$.
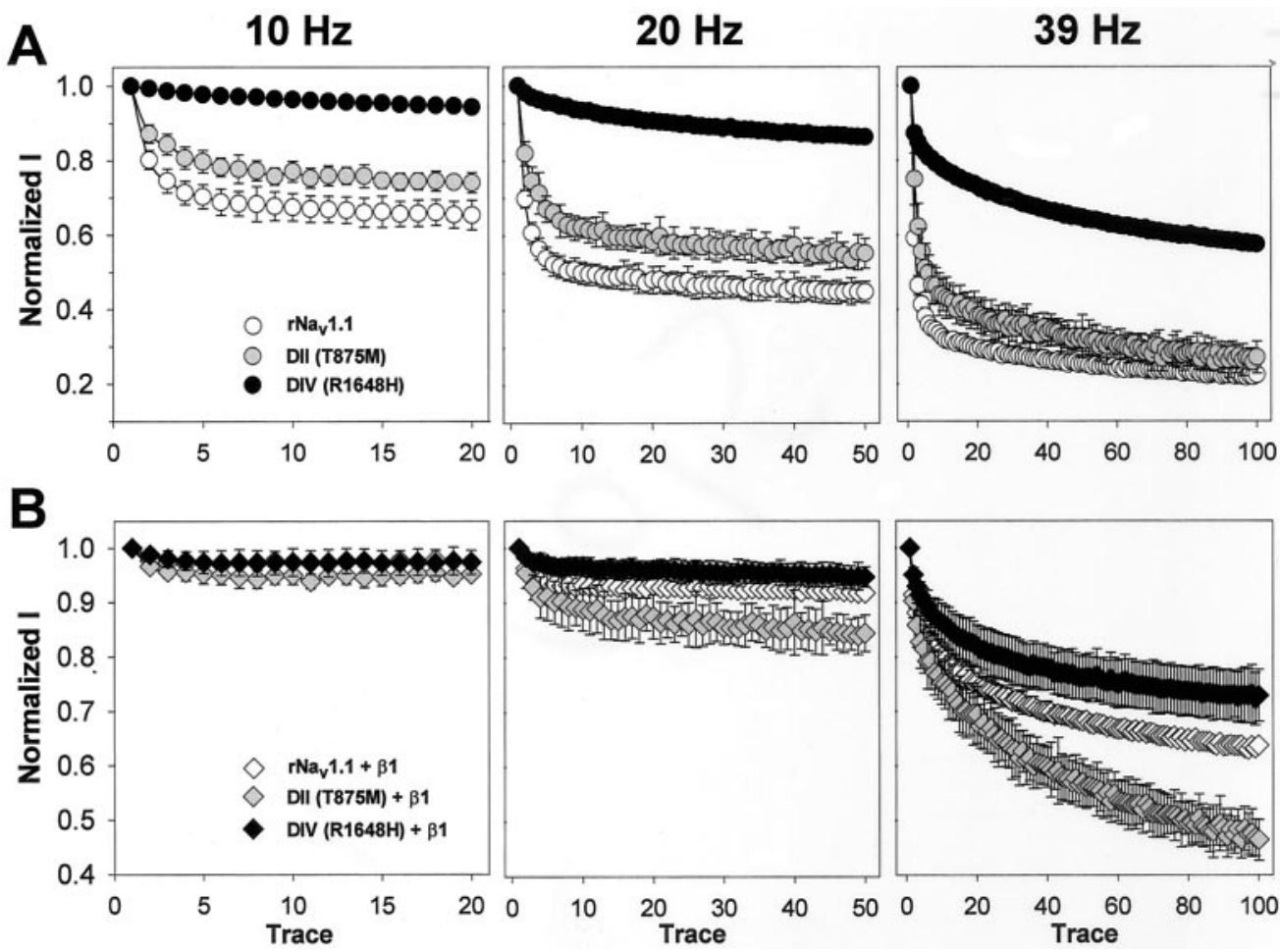

current recovering with that time constant was similar for both channels. The second time constant of recovery $\left(\tau_{2}\right)$ was also faster for the DIV mutant as compared with the wild-type $\mathrm{rNa}_{\mathrm{v}} 1.1$ and DII mutant channels.

\section{Both GEFS + 2 mutants display altered frequency dependence as compared with wild-type $\mathrm{rNa}_{\mathrm{v}} \mathbf{1 . 1}$}

An alternative way to evaluate recovery from inactivation is to examine the use or frequency dependence of sodium current amplitudes during a series of depolarizations. If there is insufficient time for complete recovery between each depolarization, then the magnitude of the current will decrease with successive depolarizations. Therefore, we examined the frequency dependence of both GEFS +2 mutants in the absence and presence of the $\beta 1$ subunit at 10,20 , and $39 \mathrm{~Hz}$, as described in Materials and Methods (Fig. 5).

When expressed as $\alpha$ subunits alone (Fig. 5A), the DIV mutant (black circles) maintained the highest level of current, with the DII mutant (gray circles) next, and the wild-type $\mathrm{rNa}_{\mathrm{v}} 1.1$ channel (white circles) least at all frequencies. At $10 \mathrm{~Hz}$ the DIV mutant showed little-to-no use-dependent decrease in current and was capable of maintaining $94 \pm 1 \%$ of the maximum current for up to $2 \mathrm{sec}$ (20 depolarizations). The DII mutant showed some use dependence at $10 \mathrm{~Hz}$, reaching an equilibrium level of $74 \pm 3 \%$ 
of the maximum current, which was still significantly higher than the wild-type $\mathrm{rNa}_{\mathrm{v}} 1.1$ channel, which reached equilibrium at $65 \pm$ $4 \%$ of the maximum current level. At $20 \mathrm{~Hz}$ the DIV mutant showed some use dependence during the $2.5 \mathrm{sec}$ protocol, reaching an equilibrium current level of $86 \pm 1 \%$ of the initial peak current amplitude, as compared with $55 \pm 4 \%$ for the DII mutant and only $45 \pm 3 \%$ for the wild-type $\mathrm{rNa}_{\mathrm{v}} 1.1$. At $39 \mathrm{~Hz}$ the DIV mutant demonstrated significant use dependence, with an equilibrium current of $58 \pm 1 \%$ of the initial peak amplitude, but this level was still more than twofold higher than the equilibrium observed for both the DII mutant and wild-type $\mathrm{rNa}_{\mathrm{v}} 1.1$ channel, which reached levels of $27 \pm 4$ and $22 \pm 1 \%$, respectively. Although the DII mutant reached an equilibrium current level similar to that of the wild-type $\mathrm{rNa}_{\mathrm{v}} 1.1$ after $2.5 \mathrm{sec}$ at $39 \mathrm{~Hz}$, the mutant channel maintained a slightly higher level of current during the first second.

When the channels were coexpressed with the $\beta 1$ subunit, both GEFS +2 mutants and the wild-type $\mathrm{rNa}_{\mathrm{v}} 1.1$ channels displayed less use dependence as compared with $\alpha$ subunits alone (Fig. $5 B$ ). At $10 \mathrm{~Hz}$ the DIV mutant (black diamonds), the DII mutant (gray diamonds), and wild-type $\mathrm{rNa}_{\mathrm{v}} 1.1$ (white diamonds) showed no significant use dependence, with equilibrium current levels of $97 \pm 2,95 \pm 1$, and $97 \pm 1 \%$ of the initial peak current amplitudes, respectively. At $20 \mathrm{~Hz}$ both the DIV mutant and wild-type $\mathrm{rNa}_{\mathrm{v}} 1.1$ displayed similar equilibrium current levels, with the DIV mutant maintaining $94 \pm 2 \%$ and wild-type $\mathrm{rNa}_{\mathrm{v}} 1.1$ maintaining $92 \pm 1 \%$ of the initial current amplitudes. The DII mutant demonstrated more pronounced use dependence, with an equilibrium level of $84 \pm 3 \%$ of the initial peak current amplitude. At the highest frequency that was tested, $39 \mathrm{~Hz}$, the three channels displayed significantly different levels of use dependence. The DIV mutant displayed the least use dependence, maintaining $73 \pm 5 \%$ of the initial peak amplitude as compared with $64 \pm 1 \%$ for the wild-type $\mathrm{rNa}_{\mathrm{v}} 1.1$ and $46 \pm 4 \%$ for the DII mutant.

These results show that the DIV mutant is capable of carrying a larger amount of current than the wild-type $\mathrm{rNa}_{\mathrm{v}} 1.1$ channel at high frequencies of depolarization when expressed as either the $\alpha$ subunit alone or as $\alpha+\beta 1$ subunits. This property is consistent with a phenotype of hyperexcitability. The DII mutant is capable of carrying a larger amount of current than the wild-type $\mathrm{rNa}_{\mathrm{v}} 1.1$ channel at low frequencies of depolarization and at early times during high frequencies of depolarization when expressed as the $\alpha$ subunit alone, but this effect is reversed when the $\beta 1$ subunit is coexpressed.

\section{The DII mutant displays enhanced slow inactivation as compared with wild-type $\mathrm{rNa}_{\mathrm{v}} \mathbf{1 . 1}$}

In addition to the fast-gated properties examined above, sodium channels undergo slow-gated transitions that occur on the time scale of seconds to minutes. Several disease-causing mutations in the skeletal muscle sodium channel $\mathrm{Na}_{\mathrm{v}} 1.4$ have been reported to disrupt the voltage dependence of slow inactivation, disrupt entry into the slow-inactivated state, or enhance recovery from slow inactivation (for review, see Cannon, 2000). Because the fastgated properties of the DII mutant were very similar to those of the wild-type channel, it seemed likely that this mutation might have more of an effect on slow inactivation. Therefore, we examined the voltage dependence of slow inactivation, the rate of entry into the slow-inactivated state, and recovery from slow inactivation of both GEFS +2 mutants in comparison to wild-type
$\mathrm{rNa}_{\mathrm{v}} 1.1$ in the presence of the $\beta 1$ subunit, as described in Materials and Methods (Fig. 6, Table 2).

The voltage dependence of slow inactivation of the DII mutant (Fig. 6A, gray circles) was shifted $10 \mathrm{mV}$ in the negative direction when compared with both the DIV mutant (black circles) and wild-type $\mathrm{rNa}_{\mathrm{v}} 1.1$ (white circles). The DII mutant also displayed a significantly steeper slope (Table 2), thus inactivating over a smaller voltage range than wild-type $\mathrm{rNa}_{\mathrm{v}} 1.1$. Interestingly, the DIV mutant also displayed a significantly steeper slope that was similar to that of the DII mutant, but the $V_{1 / 2}$ of slow inactivation was similar to that of wild-type $\mathrm{rNa}_{\mathrm{v}} 1.1$

Both GEFS +2 mutants and wild-type $\mathrm{rNa}_{\mathrm{v}} 1.1$ displayed biphasic recovery from the slow-inactivated state (Fig. 6B, Table 2). The DIV mutant (black circles), which was shown to recover from fast inactivation more rapidly than wild-type $\mathrm{rNa}_{\mathrm{v}} 1.1$, recovered from slow inactivation in a manner that was very similar to that of wild-type $\mathrm{rNa}_{\mathrm{v}} 1.1$ (white circles). However, the DII mutant (gray circles $)$ displayed a significantly slower slow component $\left(\tau_{\text {slow }}\right)$ of recovery than that of wild-type $\mathrm{rNa}_{\mathrm{v}} 1.1$ (Table 2). This effect resulted in less complete recovery by $60 \mathrm{sec}$ at $-120 \mathrm{mV}$, reaching only $87 \pm 5 \%$ recovery for the DII mutant as compared with $97 \pm$ $1 \%$ for the wild-type channels.

The rate of entry into the slow-inactivated state for both GEFS +2 mutants and wild-type $\mathrm{rNa}_{\mathrm{v}} 1.1$ also followed a biphasic time course (Fig. 6C,D, Table 2). Entry into slow inactivation was tested at two potentials, -45 and $-10 \mathrm{mV}$. At $-45 \mathrm{mV}$ both the DIV mutant (black circles) and wild-type $\mathrm{rNa}_{\mathrm{v}} 1.1$ (white circles) displayed significantly less slow inactivation as compared with the DII mutant (gray circles). The DII mutant resulted in a more complete slow inactivation by inactivating a significantly larger percentage of current with the fast time component $\left(\tau_{\text {Fast }}\right)$ as compared with both wild-type $\mathrm{rNa}_{\mathrm{v}} 1.1$ and the DIV mutant. The magnitude of the fast time constant was comparable for all three channels. The DII mutant inactivated the remainder of the current with a significantly more rapid slow time constant $\left(\tau_{\text {Slow }}\right)$ as compared with both the DIV mutant and wild-type $\mathrm{rNa}_{\mathrm{v}} 1.1$ (Table 2). The DII mutant fully inactivated in $60 \mathrm{sec}$, whereas the DIV mutant and wild-type $\mathrm{rNa}_{\mathrm{v}} 1.1$ channels did not, consistent with the results examining the voltage dependence of slow inactivation (Fig. 6A).

At $-10 \mathrm{mV}$ all of the channels inactivated more rapidly than at $-45 \mathrm{mV}$, which was expected. However, the DII mutant channel still demonstrated more rapid entry into the slow-inactivated state. At $-10 \mathrm{mV}$ the DII mutant displayed a larger percentage of current inactivating with a faster $\tau_{\text {Fast }}$ as compared with wild-type $\mathrm{rNa}_{\mathrm{v}} 1.1$ (Table 2). The DIV mutant also displayed a faster $\tau_{\text {Fast }}$ at $-10 \mathrm{mV}$, but it was otherwise similar to wild-type $\mathrm{rNa}_{\mathrm{v}} 1.1$. All three channels inactivated completely within $30 \mathrm{sec}$, consistent with the results examining the voltage dependence of slow inactivation (Fig. 6A).

\section{DISCUSSION}

We have shown that two sodium channel mutations that cause GEFS +2 alter the function of the channels. Each mutation was cloned into the orthologous rat sodium channel $\left(\mathrm{rNa}_{\mathrm{v}} 1.1\right)$ and expressed in Xenopus oocytes. Mutant channels were expressed at comparable levels to the wild-type $\mathrm{rNa}_{\mathrm{v}} 1.1$ channel, indicating that the mutations had no significant effects on the translation or processing of the channel proteins.

The two mutations had different effects on the properties of the sodium channel. The DIV mutation accelerated recovery from inactivation (see Fig. 4) and decreased use dependence (see Fig. 
Figure 6. Slow-gated properties of wild-type $\mathrm{rNa}_{\mathrm{v}} 1.1$ and GEFS +2 mutant channels. The slow-gated properties were determined for the wild-type $\mathrm{rNa}_{\mathrm{v}} 1.1$ (white circles), DII ( gray circles), and DIV (black circles) mutants expressed as $\alpha+\beta 1$ subunits. The voltage dependence of slow inactivation $(A)$ was analyzed by using a two-step protocol consisting of $60 \mathrm{sec}$ depolarizations from a holding potential of $-120 \mathrm{mV}$ to a range of potentials between -120 and $-10 \mathrm{mV}$, followed by a hyperpolarization to $-120 \mathrm{mV}$ for $20 \mathrm{msec}$ to allow for recovery from fast inactivation and a test pulse to $-5 \mathrm{mV}$. The data were fit with a two-state Boltzmann equation, as described in Materials and Methods, and the parameters of the fits are shown in Table 2. The recovery from slow inactivation $(B)$ was analyzed by using two separate two-pulse protocols consisting of a $60 \mathrm{sec}$ depolarization to $-5 \mathrm{mV}$ from a holding potential of $-120 \mathrm{mV}$, followed by a variable recovery time at $-120 \mathrm{mV}$, a hyperpolarization to $-120 \mathrm{mV}$ to allow for recovery from fast inactivation, and a test depolarization to $-5 \mathrm{mV}$. The data were fit with a double exponential equation, as described in Materials and Methods, and the parameters of the fits are shown in Table 2. The rate of entry into the slow-inactivated state $(C, D)$ was analyzed by using a two-step protocol consisting of a variable length conditioning pulse at either -45 or $-10 \mathrm{mV}$ from a holding potential of $-120 \mathrm{mV}$, followed by a hyperpolarization to $-120 \mathrm{mV}$ to allow for recovery from fast inactivation and a test depolarization to -5 $\mathrm{mV}$. The data were fit with a double exponential decay, as described in Materials and Methods, and the parameters of the fits are shown in Table 2. For each graph the values shown are averages; the error bars indicate SD.
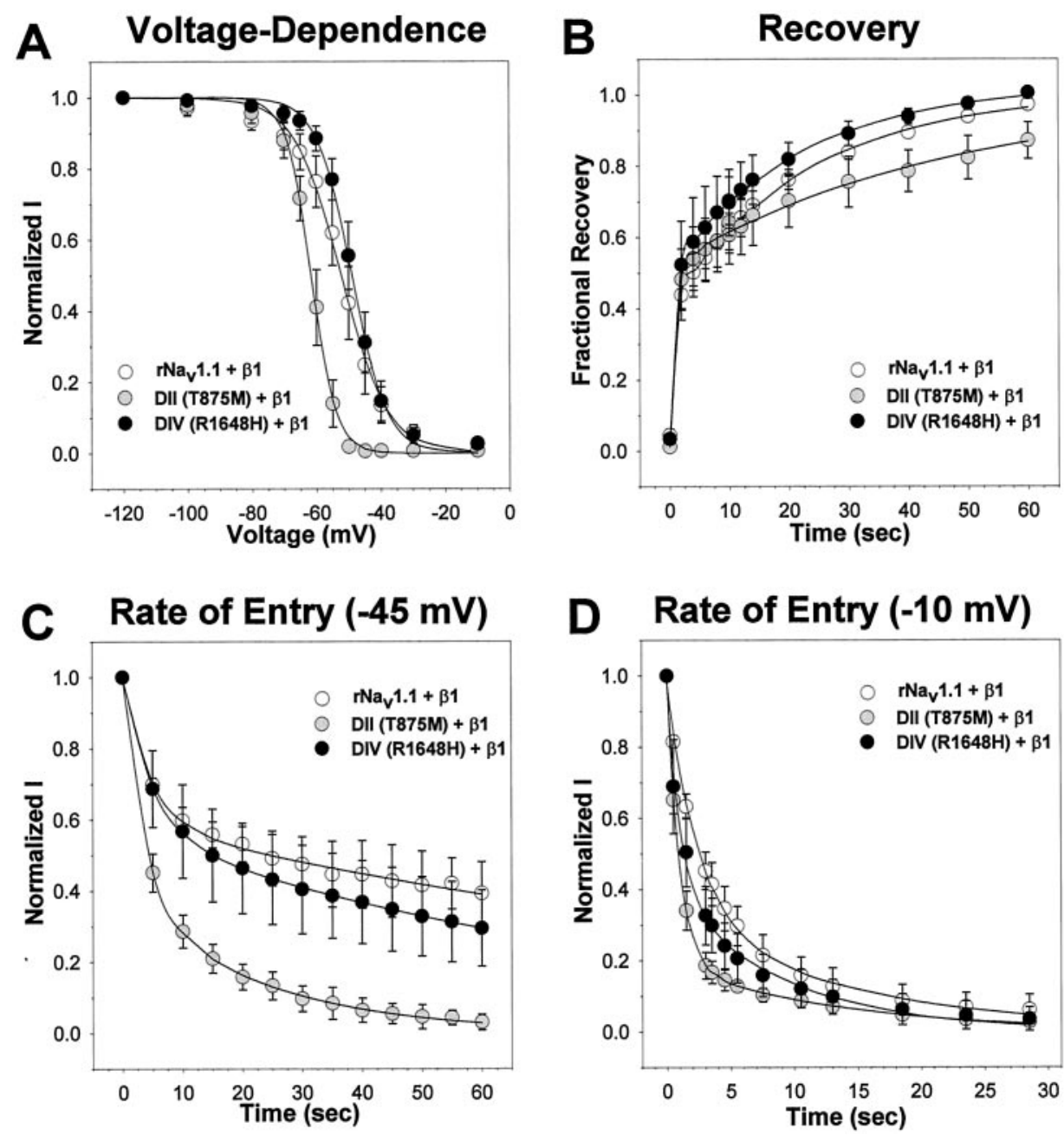
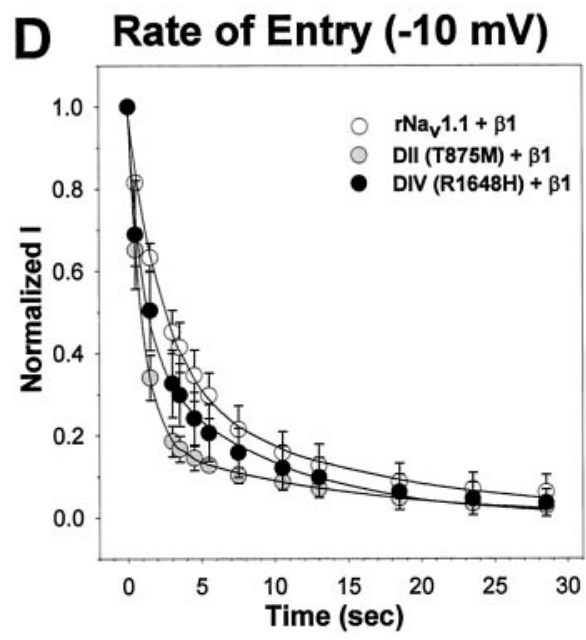

Table 2. Parameters of slow inactivation

\begin{tabular}{|c|c|c|c|c|c|c|c|c|c|c|c|c|c|c|}
\hline \multirow[b]{3}{*}{ Channel } & \multirow{2}{*}{\multicolumn{3}{|c|}{$\begin{array}{l}\text { Voltage dependence of } \\
\text { slow inactivation }\end{array}$}} & \multicolumn{6}{|c|}{ Entry into slow inactivation } & \multicolumn{5}{|c|}{ Recovery from slow inactivation } \\
\hline & & & & \multirow[b]{2}{*}{$\begin{array}{l}V \\
(\mathrm{mV})\end{array}$} & \multicolumn{2}{|l|}{$\tau_{\text {fast }}$} & \multicolumn{2}{|l|}{$\tau_{\text {slow }}$} & & \multicolumn{2}{|l|}{$\tau_{\text {fast }}$} & \multicolumn{3}{|l|}{$\tau_{\text {slow }}$} \\
\hline & $V_{1 / 2}(\mathrm{mV})$ & $z\left(e_{0}\right)$ & $n$ & & $\mathrm{Sec}$ & $\begin{array}{l}\text { Per- } \\
\text { centage }\end{array}$ & $\mathrm{Sec}$ & $\begin{array}{l}\text { Per- } \\
\text { centage }\end{array}$ & $n$ & $\mathrm{Sec}$ & $\begin{array}{l}\text { Per- } \\
\text { centage }\end{array}$ & $\mathrm{Sec}$ & $\begin{array}{l}\text { Per- } \\
\text { centage }\end{array}$ & $n$ \\
\hline & & & & -45 & $4.8 \pm 1.9$ & $42 \pm 8$ & $165 \pm 61$ & $58 \pm 8$ & 4 & & & & & \\
\hline \multirow[t]{2}{*}{$\mathrm{rNa}_{\mathrm{v}} 1.1+\beta 1$} & $-52.3 \pm 2.8$ & $7.0 \pm 0.9$ & 5 & -10 & $2.4 \pm 0.3$ & $63 \pm 3$ & $14.3 \pm 6.1$ & $35 \pm 2$ & 5 & $0.7 \pm 0.4$ & $39 \pm 8$ & $25.0 \pm 5.2$ & $60 \pm 10$ & 4 \\
\hline & & & & -45 & $3.3 \pm 1.1$ & $59 \pm 8^{*}$ & $23.2 \pm 8.7^{*}$ & $41 \pm 8^{*}$ & 4 & & & & & \\
\hline \multirow[t]{2}{*}{$\mathrm{DII}+\beta 1$} & $-61.6 \pm 1.5^{*}$ & $3.7 \pm 0.3^{*}$ & 5 & -10 & $1.0 \pm 0.1^{*}$ & $81 \pm 5^{*}$ & $13.8 \pm 2.7$ & $19 \pm 4^{*}$ & 4 & $1.0 \pm 0.1$ & $52 \pm 9$ & $46.1 \pm 8.3^{*}$ & $48 \pm 8$ & 5 \\
\hline & & & & -45 & $5.1 \pm 1.2$ & $44 \pm 14$ & $96.1 \pm 32.0$ & $56 \pm 14$ & 7 & & & & & \\
\hline $\mathrm{DIV}+\beta 1$ & $-48.9 \pm 1.8$ & $5.3 \pm 0.9^{*}$ & 5 & -10 & $1.1 \pm 0.8^{*}$ & $58 \pm 10$ & $9.9 \pm 6.3$ & $42 \pm 10$ & 5 & $0.7 \pm 0.1$ & $49 \pm 16$ & $23.3 \pm 4.4$ & $52 \pm 15$ & 5 \\
\hline
\end{tabular}

*Indicates a statistically significant difference from wild-type $\mathrm{rNa}_{\mathrm{v}} 1.1 \alpha+\beta 1$ at $p<0.05$.

5). The mutant channels displayed a much more rapid twocomponent recovery from inactivation when expressed both as the $\alpha$ subunit alone and when coexpressed with the $\beta 1$ subunit. This more rapid recovery would make the mutant channels available to initiate and propagate action potentials at a higher frequency during a sustained depolarization. The ability of the DIV mutant channels to sustain a rapid train of action potential firing was demonstrated by their reduced frequency dependence. The ability of the mutant channel to carry more current than the wild-type channel at each frequency most likely results from the more rapid recovery of the mutant channel from inactivation. At
$10 \mathrm{~Hz}$ the DIV mutant is capable of maintaining $\sim 100 \%$ of the initial current for up to $2 \mathrm{sec}$ in both the absence and presence of the $\beta 1$ subunit. At this frequency the start-to-start interval of each successive depolarization is $100 \mathrm{msec}$, a time span that is sufficient for the DIV mutant channels to recover fully from inactivation. This correlation between frequency dependence and recovery time is also true for the higher frequencies of 20 and 39 $\mathrm{Hz}$. In neurons firing action potentials in rapid succession, the DIV mutant channels that open and inactivate during a given action potential would recover from inactivation and be ready to participate in the firing of a second action potential 2- to 10 -fold 
faster than the wild-type channels. These effects are consistent with the GEFS +2 phenotype of hyperexcitability.

The DII mutation had minor effects on fast-gated properties, but it greatly enhanced slow inactivation (see Fig. 6). There were two effects on fast-gated properties. First, recovery from inactivation was slower for the DII mutant channels as compared with the wild-type channels when the $\alpha$ subunits were expressed alone, but not when the channels were coexpressed with the $\beta 1$ subunit. Second, the DII mutant channels showed less use dependence than the wild-type channels when the $\alpha$ subunits were expressed alone but more use dependence when the $\beta 1$ subunit was present. The increased use dependence probably results from enhanced entry into the slow-inactivated state, because the DII mutant and wild-type channels recovered from fast inactivation with similar kinetics. At $39 \mathrm{~Hz}$ with $17.5 \mathrm{msec}$ depolarizations to $-10 \mathrm{mV}$, the channels spend most of the $2.56 \mathrm{sec}$ protocol at $-10 \mathrm{mV}$. A single depolarization to $-10 \mathrm{mV}$ for $1.5 \mathrm{sec}$ reduced the available current to $63 \pm 4 \%$ for the wild-type channels and to $34 \pm 5 \%$ for the DII mutant channels (see Fig. 6D). After approximately the same time in the use dependence protocol (58 depolarizations), the current amplitude was reduced to $67 \pm 1 \%$ for wild-type $\mathrm{rNa}_{\mathrm{v}} 1.1$ and to $53 \pm 4 \%$ for the DII mutant (see Fig. 5B). Therefore, the decrease in current during a series of rapid depolarizations is comparable to the decrease during a single long depolarization. This correlation between enhanced slow inactivation and increased use dependence has been reported by Struyk et al. (2000) for the hypokalemic periodic paralysis mutation $\mathrm{R} 669 \mathrm{H}$ in DIIS4 of $\mathrm{hNa}_{\mathrm{v}} 1.4$ and by Wang and Wang (1997) for the N434A mutation in DIS6 of $\mathrm{rNa}_{\mathrm{v}} 1.4$. Each of these mutations shifted the voltage dependence of slow inactivation in the hyperpolarized direction, accelerated entry into the slow-inactivated state, slowed recovery from slow inactivation, and increased use dependence.

Enhanced slow inactivation is more consistent with a phenotype of hypoexcitability rather than hyperexcitability, which is contrary to what would be expected for a mutation that causes epilepsy. An extended depolarization to a potential that elicits slow inactivation would result in more extensive slow inactivation of the DII mutant channels, which would decrease the ability of the neuron to fire action potentials at high frequency. However, several skeletal muscle sodium channel mutations that cause hypokalemic periodic paralysis with myotonia have been shown to cause enhanced slow inactivation (Takahashi and Cannon, 1999; Jurkat-Rott et al., 2000; Struyk et al., 2000). In addition, decreased sodium channel activity can cause epilepsy, as demonstrated by null mutations in the $S C N 1 A$ gene in patients with severe myoclonic epilepsy of infancy (Claes et al., 2001). One possibility is that seizure activity results from decreased firing of inhibitory neurons, which causes increased firing in postsynaptic neurons.

The fact that the effects of the DIV mutation are more consistent with hyperexcitability than those of the DII mutation is consistent with the differences in clinical severity of the two GEFS + 2 mutations (Baulac et al., 1999; Moulard et al., 1999; Escayg et al., 2000). The DIV mutation results in more severe clinical sequelae, as assessed by the presence of afebrile and generalized seizures. In a family with the DIV R1648H mutation, 11 of 12 affected individuals presented with generalized epilepsy in addition to febrile seizures (Baulac et al., 1999; Escayg et al., 2000). In contrast, only 5 of 11 affected individuals with the DII T875M mutation presented with afebrile seizures and generalized epilepsy (Moulard et al., 1999; Escayg et al., 2000).
Many antiepileptic drugs such as phenytoin, carbamazepine, and valproic acid are known to block sodium channels in a use-dependent manner (Dichter, 1991; Macdonald and Kelly, 1994), thus reducing the equilibrium current maintained during high frequency depolarizations. These drugs slow recovery from inactivation of wild-type sodium channels by binding to and stabilizing the inactivated state (McLean and Macdonald, 1986; Macdonald and Kelly, 1994; Kuo and Lu, 1997). The result is a use-dependent block that reduces the ability of the channel to maintain high-frequency action potential firing during sustained membrane depolarization. These drugs have been thought to reduce seizure activity by decreasing the excitability of sodium channels downstream of the actual cause of the seizure. The results for the DIV mutant suggest that these drugs also may act directly on hyperexcitable sodium channels in patients with GEFS+ 2 .

The arginine in the $\mathrm{S} 4$ segment of DIV (R1648 in $\left.\mathrm{rNa}_{\mathrm{v}} 1.1\right)$ is absolutely conserved in mammalian and invertebrate voltagegated sodium channels (Goldin, 1999; Escayg et al., 2000). The effects of substituting histidine for this arginine have been examined by a number of investigators, and the effects have varied depending on the sodium channel isoform that has been examined. With respect to voltage dependence, we have shown that $\mathrm{R} 1648 \mathrm{H}$ in $\mathrm{rNa}_{\mathrm{v}} 1.1$ shifts the voltage dependence of inactivation slightly in the hyperpolarized direction without affecting the voltage dependence of activation when expressed as an $\alpha$ subunit alone. When coexpressed with the $\beta 1$ subunit, there were no significant effects on the voltage dependence of activation or inactivation. Kühn and Greeff (1999) analyzed the same arginineto-histidine mutation in $\mathrm{rNa}_{\mathrm{v}} 1.2(\mathrm{R} 1638 \mathrm{H})$ with Xenopus oocytes. They observed a shift in the opposite (depolarized) direction for the voltage dependence of inactivation, with no shift in the current-voltage relationship when the $\alpha$ subunit was expressed alone. Alekov et al. (2000) studied the comparable mutation $(\mathrm{R} 1460 \mathrm{H})$ in the $\mathrm{hNa}_{\mathrm{v}} 1.4$ skeletal muscle sodium channel in tsA201 cells. They observed shifts in the negative direction for the voltage dependence of activation and inactivation. Neither Kühn and Greeff (1999) nor Alekov et al. (2000) examined the mutant channels in the presence of the $\beta 1$ subunit.

With respect to kinetics, we have shown that the $\mathrm{R} 1648 \mathrm{H}$ mutation in $\mathrm{rNa}_{\mathrm{v}} 1.1$ dramatically accelerates recovery from inactivation in both the absence and presence of the $\beta 1$ subunit, with a slight slowing of inactivation when the $\alpha$ subunit is expressed alone. The results of Alekov et al. (2000) for the R1460H mutation in $\mathrm{hNa}_{\mathrm{v}} 1.4$ are similar to our data, with slightly slower inactivation and markedly faster recovery from inactivation when the $\alpha$ subunits were expressed alone. Kühn and Greeff (1999) observed no significant effects of the corresponding $\mathrm{R} 1638 \mathrm{H}$ mutation in $\mathrm{rNa}_{\mathrm{v}} 1.2$ on the time course of recovery from inactivation when the $\alpha$ subunits were expressed alone. With respect to the phenotype of GEFS +2 , we believe that the most relevant results are those obtained by using the orthologous channel in the presence of the $\beta 1$ subunit, in which case the most dramatic effect is a significant acceleration in recovery from inactivation. However, it is possible that the presence of either the $\beta 2$ or $\beta 3$ subunits might alter channel function to result in other differences between the mutant and wild-type channels.

In summary, we have shown that two $S C N 1 A$ mutations that were identified previously as causing GEFS +2 alter the electrophysiological properties of the sodium channel. The DIV mutation accelerated recovery from inactivation and reduced the frequency dependence of the channel, whereas the DII mutation 
enhanced slow inactivation and increased the frequency dependence of the channel. The DIV mutation results in a phenotype of hyperexcitability, whereas the DII mutation results in a phenotype of hypoexcitability, suggesting that either an increase or decrease in sodium channel activity can result in seizures. Additional mutations in SCN1A that cause GEFS + 2 (Escayg et al., 2001; Wallace et al., 2001) and a mutation in $S C N 2 A$ that causes febrile seizures associated with afebrile seizures (Sugawara et al., 2001) have been identified since, making it likely that there will be even more mechanisms by which sodium channel alterations cause epilepsy. Understanding these mechanisms should provide important insights into the etiology of epilepsy in GEFS +2 patients and facilitate the development of animal models for the study of GEFS +2 and targeted drug discovery.

\section{REFERENCES}

Alekov AK, Rahman MM, Mitrovic N, Lehmann-Horn F, Lerche H (2000) A sodium channel mutation causing epilepsy in man exhibits defects in fast inactivation and inactivation in vitro. $\mathrm{J}$ Physiol (Lond) 529:533-539.

Baulac S, Gourfinkel-An I, Picard F, Rosenberg-Bourgin M, Prud'homme J-F, Baulac M, Brice A, LeGuern E (1999) A second locus for familial generalized epilepsy with febrile seizures plus maps to chromosome 2q21-q33. Am J Hum Genet 65:1078-1085.

Cannon SC (2000) Spectrum of sodium channel disturbances in the nondystrophic myotonias and periodic paralyses. Kidney Int 57:772-779.

Chen Q, Kirsch GE, Zhang D, Brugada R, Brugada J, Brugada P, Potenza D, Moya A, Borggrefe M, Breithardt G, Ortiz-Lopez R, Wang Z, Antzelevitch C, O'Brien RE, Schulze-Bahr E, Keating MT, Towbin JA, Wang Q (1998) Genetic basis and molecular mechanism for idiopathic ventricular fibrillation. Nature 392:293-296.

Claes L, Del-Favero J, Cuelemans B, Lagae L, Van Broeckhoven C, De Jonghe P (2001) De novo mutations in the sodium-channel gene $S C N 1 A$ cause severe myoclonic epilepsy of infancy. Am J Hum Genet 68:1327-1332.

Commission on Classification and Terminology of the International League Against Epilepsy (1989) Proposal for revised classification of epilepsies and epileptic syndromes. Epilepsia 30:389-399.

Dichter MA (1991) The epilepsies and convulsive disorders. In: Harrison's principles of internal medicine (Wilson JD, Braunwald E, Isselbacher KJ, Petersdorf RG, Martin JB, Fauci AS, Root RK, eds), pp 1968-1977. New York: McGraw-Hill.

Dichter MA (1994) Emerging insights into mechanisms of epilepsy: implications for new antiepileptic drug development. Epilepsia 35:S51-S57.

Escayg A, MacDonald BT, Meisler MH, Baulac S, Huberfeld G, AnGourfinkel I, Brice A, LeGuern E, Moulard B, Chaigne D, Buresi C, Malafosse A (2000) Mutations of $S C N 1 A$, encoding a neuronal sodium channel, in two families with GEFS+ 2. Nat Genet 24:343-345.

Escayg A, Heils A, MacDonald BT, Haug K, Sander T, Meisler MH (2001) A novel SCN1A mutation associated with generalized epilepsy with febrile seizures plus and prevalence of variants in patients with epilepsy. Am J Hum Genet 68:866-873.

Goldin AL (1991) Expression of ion channels by injection of mRNA into Xenopus oocytes. Methods Cell Biol 36:487-509.

Goldin AL (1999) Diversity of mammalian voltage-gated sodium channels. In: Molecular and functional diversity of ion channels and receptors (Rudy B, Seeburg P, eds), pp 38-50. New York: New York Academy of Sciences.

Hayward LJ, Brown Jr RH, Cannon SC (1996) Inactivation defects caused by myotonia-associated mutations in the sodium channel III-IV linker. J Gen Physiol 107:559-576.

Jurkat-Rott K, Mitrovic N, Hang C, Kouzmekine A, Iaizzo P, Herzog J, Lerche H, Nicole S, Vale-Santos J, Chauveau D, Fontaine B, LehmannHorn F (2000) Voltage-sensor sodium channel mutations cause hy- pokalemic periodic paralysis type 2 by enhanced inactivation and reduced current. Proc Natl Acad Sci USA 97:9549-9554.

Kontis KJ, Rounaghi A, Goldin AL (1997) Sodium channel activation gating is affected by substitutions of voltage sensor positive charges in all four domains. J Gen Physiol 110:391-401.

Kühn FJP, Greeff NG (1999) Movement of voltage sensor S4 in domain 4 is tightly coupled to sodium channel fast inactivation and gating charge immobilization. J Gen Physiol 114:167-183.

Kuo C-C, Lu L (1997) Characterization of lamotrigine inhibition of $\mathrm{Na}^{+}$channels in rat hippocampal neurones. $\mathrm{Br} \mathrm{J}$ Pharmacol 121:1231-1238.

Lopes-Cendes I, Scheffer IE, Berkovic SF, Rousseau M, Andermann E Rouleau GA (2000) A new locus for generalized epilepsy with febrile seizures plus maps to chromosome 2. Am J Hum Genet 66:698-701.

Macdonald RL, Kelly KM (1994) Mechanisms of action of currently prescribed and newly developed antiepileptic drugs. Epilepsia 35:S41-S50.

McLean MJ, Macdonald RL (1986) Carbamazepine and 10,11epoxycarbamazepine produce use- and voltage-dependent limitation of rapidly firing action potentials of mouse central neurons in cell culture. J Pharmacol Exp Ther 238:727-738.

Moran O, Conti F (2001) Skeletal muscle sodium channel is affected by an epileptogenic $\beta 1$ subunit mutation. Biochem Biophys Res Commun 282:55-59.

Moulard B, Guipponi M, Chaigne D, Mouthon D, Buresi C, Malafosse A (1999) Identification of a new locus for generalized epilepsy with febrile seizures plus (GEFS+) on chromosome 2q24-q33. Am J Hum Genet 65:1396-1400.

Nelson KB, Ellenberg JH (1976) Predictors of epilepsy in children who have experienced febrile seizures. N Engl J Med 295:1029-1033.

Patton DE, Goldin AL (1991) A voltage-dependent gating transition induces use-dependent block by tetrodotoxin of rat IIA sodium channels expressed in Xenopus oocytes. Neuron 7:637-647.

Scheffer IE, Berkovic SF (1997) Generalized epilepsy with febrile seizures plus. A genetic disorder with heterogeneous clinical phenotypes. Brain 120:479-490.

Singh R, Scheffer IE, Crossland K, Berkovic SF (1999) Generalized epilepsy with febrile seizures plus: a common childhood-onset genetic epilepsy syndrome. Ann Neurol 45:75-81.

Smith MR, Goldin AL (1999) A mutation that causes ataxia shifts the voltage dependence of the Scn8a sodium channel. NeuroReport 10:3027-3031.

Smith RD, Goldin AL (1998) Functional analysis of the rat I sodium channel in Xenopus oocytes. J Neurosci 18:811-820.

Steinlein OK, Noebels JL (2000) Ion channels and epilepsy in man and mouse. Curr Opin Genet Dev 10:286-291.

Struyk AF, Scoggan KA, Bulman DE, Cannon SC (2000) The human skeletal muscle Na channel mutation $\mathrm{R} 669 \mathrm{H}$ associated with hypokalemic periodic paralysis enhances slow inactivation. $\mathrm{J}$ Neurosci 20:8610-8617.

Sugawara T, Tsurubuchi Y, Agarwala KL, Ito M, Fukuma G, MazakiMiyazaki E, Nagafuji H, Noda M, Imoto K, Wada K, Mitsudome A, Kaneko S, Montal M, Nagata K, Hirose S, Yamakawa K (2001) A missense mutation of the $\mathrm{Na}^{+}$channel $\alpha_{\text {II }}$ subunit gene Nav1.2 in a patient with febrile and afebrile seizures causes channel dysfunction. Proc Natl Acad Sci USA 98:6384-6389.

Takahashi MP, Cannon SC (1999) Enhanced slow inactivation by V445M: a sodium channel mutation associated with myotonia. Biophys J 76:861-868.

Wallace RH, Wang DW, Singh R, Scheffer IE, George Jr AL, Phillips HA, Saar K, Reis A, Johnson EW, Sutherland GR, Berkovic SF Mulley JC (1998) Febrile seizures and generalized epilepsy associated with a mutation in the $\mathrm{Na}^{+}$channel $\beta 1$ subunit gene $S C N 1 B$. Nat Genet 19:366-370.

Wallace RH, Scheffer IE, Barnett S, Richards M, Dibbens L, Desai RR, Lerman-Sadie T, Lev D, Mazarib A, Brand N, Ben-Zeev B, Goikhman I, Singh R, Kremmidiotis G, Gardner A, Sutherland GR, George Jr AL, Mulley JC, Berkovic SF (2001) Neuronal sodium channel $\alpha 1$ subunit mutations in generalized epilepsy with febrile seizures plus. Am J Hum Genet 68:859-865

Wang S-Y, Wang GK (1997) A mutation in segment I-S6 alters slow inactivation of sodium channels. Biophys $\mathrm{J}$ 72:1633-1640. 